\section{Military Technical College Kobry El-Kobbah, Cairo, Egypt.}

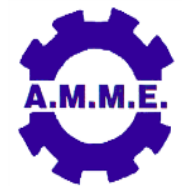

$18^{\text {th }}$ International Conference on Applied Mechanics and Mechanical Engineering.

\title{
COMPUTATIONAL FLUID DYNAMICS AND COMBUSTION MODELLING
}

\author{
S. S. Ibrahim
}

\begin{abstract}
This lecture describes recent numerical and experimental studies of Computational Fluid Dynamics (CFD) and combustion in practical applications. The studies have been performed in a range of laboratory platforms where controlled flow and combustion take place. The lecture will cover a wide range of practical industrial applications including burners' swirl flames, premixed and non-premixed combustion, internal combustion engines, fuel cells, hydrogen utilization and applications, dust and hydrogen safety studies.
\end{abstract}

The numerical approaches used in the above studies range from simple ones that are numerically feasible for practical applications such as those based on Reynolds Averaged Navier-Stokes (RANS) equations to complex and numerically very expensive such as Large Eddy Simulation (LES) methods. Experimentally, high speed images of flow and combustion processes as well pressure-time traces are widely available for a range of experimental conditions but flow field measurements are less common due to the seeding difficulty associated with such transient processes. This lecture will also review recent experiments where the flame front was imaged using Laser Induced Fluorescence (LIF) from the hydroxyl radical of the combustion process.

\section{KEYWORDS}

CFD modeling, burners, flames, internal combustion engines, LES simulations, hydrogen technology, industrial safety, premixed and non-premixed combustion and fuel cells.

* Assist. Prof., Department of Aeronautical and Automotive Engineering, Loughborough University, Loughborough LE11 3TU, UK 